\title{
The prevalence of growth hormone deficiency in survivors of subarachnoid haemorrhage: results from a large single centre study
}

\author{
Sumithra Giritharan ${ }^{1,7} \cdot$ Joanna Cox $^{2} \cdot$ Calvin J. Heal $^{3}$ - David Hughes ${ }^{4}$. \\ Kanna Gnanalingham ${ }^{5,6} \cdot$ Tara Kearney ${ }^{1,2}$
}

Published online: 18 August 2017

(C) The Author(s) 2017. This article is an open access publication

\begin{abstract}
Objective The variation in reported prevalence of growth hormone deficiency (GHD) post subarachnoid haemorrhage (SAH) is mainly due to methodological heterogeneity. We report on the prevalence of GHD in a large cohort of patients following SAH, when dynamic and confirmatory pituitary hormone testing methods are systematically employed.

Design In this cross-sectional study, pituitary function was assessed in 100 patients following SAH. Baseline pituitary hormonal profile measurement and glucagon stimulation testing (GST) was carried out in all patients. Isolated GHD was confirmed with an Arginine stimulation test and ACTH deficiency was confirmed with a short synacthen test.
\end{abstract}

Sumithra Giritharan

sumithra@doctors.org.uk

1 Department of Endocrinology, Salford Royal NHS Foundation Trust, Stott Lane, Salford, Greater Manchester M6 8HD, UK

2 Vascular Research Network, Salford Royal NHS Foundation Trust, Stott Lane, Salford, Greater Manchester M6 8HD, UK

3 Centre for Biostatistics, Faculty of Biology, Medicine and Health, Manchester Academic Health Science Centre, University of Manchester, Manchester, UK

4 Department of Neuroradiology, Salford Royal NHS Foundation Trust, Stott Lane, Salford, Greater Manchester M6 8HD, UK

5 Department of Neurosurgery, Salford Royal NHS Foundation Trust, Stott Lane, Salford, Greater Manchester M6 8HD, UK

6 Manchester Academic Health Sciences Centre (MAHSC), University of Manchester, Manchester, UK

7 Department of Endocrinology and Diabetes, Salford Royal NHS Foundation Trust, Stott Lane, Salford, Greater Manchester M6 8HD, UK
Results The prevalence of hypopituitarism in our cohort was $19 \%$ and the prevalence of GHD was $14 \%$. There was no association between GHD and the clinical or radiological severity of SAH at presentation, treatment modality, age, or occurrence of vasospasm. There were statistically significant differences in terms of Glasgow Outcome Scale (GOS; $p=0.03$ ) between patients diagnosed with GHD and those without. Significant inverse correlations between GH peak on GST with body mass index (BMI) and waist hip ratio (WHR) was also noted $(\mathrm{p}<0.0001$ and $\mathrm{p}<0.0001$ respectively).

Conclusion Using the current testing protocol, the prevalence of GHD detected in our cohort was $14 \%$. It is unclear if the BMI and WHR difference observed is truly due to GHD or confounded by the endocrine tests used in this protocol. There is possibly an association between the development of GHD and worse GOS score. Routine endocrine screening of all SAH survivors with dynamic tests is time consuming and may subject many patients to unnecessary side-effects. Furthermore the degree of clinical benefit derived from growth hormone replacement in this patient group, remains unclear. Increased understanding of the most appropriate testing methodology in this patient group and more importantly which SAH survivors would derive most benefit from GHD screening is required.

Keywords Subarachnoid haemorrhage .

Hypopituitarism · Growth hormone deficiency

\section{Introduction}

Subarachnoid Haemorrhage (SAH) is a rare but devastating event that occurs in about 8 to 10 per 100,000 patients per year [1]. In the past mortality was approximately $50 \%$ and 
about a third of survivors did not regain full independence [2]. Improvements in neurointensive care and the introduction of endovascular procedures have improved survival rates, with case fatality decreasing by $17 \%$ in absolute terms in the past three decades [3]. However, this improvement in mortality has unmasked the long term consequences of this life changing event. With increasing interest in patient reported quality of life as an outcome marker in the treatment of chronic diseases it is now clear that in spite of good physical and neurological outcome, a significant proportion of survivors report impaired quality of life [4-7].

Chronic sequelae of SAH include poor memory, fatigue, anxiety, depression and impaired quality of life [4, 8-11]. Undoubtedly some of the cognitive, emotional and psychosocial consequences seen in survivors of SAH resemble that of patients with untreated hypopituitarism [2], specifically Growth Hormone Deficiency (GHD). Pituitary dysfunction developing post SAH was first documented in the seminal publication of Kelly et al. [12]. Early studies have reported the prevalence of hypopituitarism in SAH survivors to be as high as 55\% [2, 13-16]. However, more recent studies report a much lower prevalence of pituitary dysfunction in this patient group [17-22] (Table 1). A recent meta-analysis has demonstrated that the pooled frequency of long term GHD is $19 \%$, however the range reported in the literature is wide, between 0 and 37\% [23].

We present the results from the screening phase of a study to assess the impact of $\mathrm{GH}$ replacement in survivors of SAH with GHD. The prevalence of GHD detected in this cohort using the testing protocol employed is reported.

\section{Subjects and methods}

\section{Patient recruitment}

This was a single centre cross sectional study of patients with SAH presenting to the regional neurosurgical centre. Patients who had received treatment for SAH between 2006 and 2014 were invited to participate 1 year or more after ictus. Study posters were also placed in a local head injury centre.

SAH was confirmed by the presence of blood on computed tomographic (CT) imaging of the brain or on cerebrospinal fluid (CSF) analysis obtained by lumbar puncture. Exclusion criteria were clinical contraindication to dynamic pituitary testing, history of cranial radiotherapy, hypothalamic/pituitary disease that was diagnosed prior to SAH and recent use of oral corticosteroids. Participants with prior history of hormonal deficiency were required to have been on stable replacement (where appropriate) for at least 3 months preceding recruitment.
This study was approved by NRES Committee North West - Greater Manchester West (Reference 14/NW/0191). All participants were required to provide written informed consent prior to study enrolment.

\section{Measures of severity of SAH}

The World Federation of Neurosurgical Societies (WFNS) grading system [24] was used to assess clinical severity of patients at presentation based on clinical information from medical records. Fisher grading system [25] was used to grade the radiological severity of SAH. If this information was not clear from the medical notes, the admission neuroimaging was reviewed by a single neuroradiologist. The location of the aneurysm, presence of hydrocephalus, insertion of extraventricular drain (EVD), presence of vasospasm and type of intervention (neurosurgical clipping or endovascular coiling) were recorded. Glasgow Outcome Scale (GOS) [26] was assessed at time of hormonal screening and graded in severity as grade 1 (death), grade 2 (persistent vegetative state), grade 3 (severe disability-conscious but disabled), grade 4 (disabled but independent as far as daily life) and grade 5 (good recovery and there may be minor deficits).

\section{Anthropometric and quality of life measures}

Body weight (measured to the nearest $0.1 \mathrm{~kg}$ using a Marsden weighing scale) and height (measured to the closest $0.5 \mathrm{~cm}$ ) were used to calculate the body mass index (BMI). Waist and hip circumference were measured to the closest $0.5 \mathrm{~cm}$ and the waist to hip ratio (WHR) was then calculated. All participants completed the quality of life in adults with growth hormone deficiency (QoL-AGHDA) questionnaire [27] at the screening visit.

\section{Clinical protocol}

All patients agreeing to take part were screened by measurement of baseline pituitary hormones (IGF-1, testosterone/ estradiol, LH, FSH, cortisol, ACTH, fT4, TSH and prolactin) and a glucagon stimulation test (GST). Given the tendency of the GST to overestimate ACTH insufficiency, all patients with a suboptimal cortisol response on GST were required to undergo a confirmatory short synacthen test (SST).

All patients with Isolated growth hormone deficiency (IGHD) were required to undergo a second confirmatory test; the arginine stimulation test (AST). Given that this was primarily a study to assess the impact of GH replacement on survivors of SAH with GHD, participants who did not demonstrate impaired quality of life on the QoLAGHDA questionnaire (and therefore did not meet the National Institute for Health and Care Excellence criteria 
Table 1 Summary of studies investigating hypopituitarism after subarachnoid haemorrhage

\begin{tabular}{|c|c|c|c|c|c|}
\hline Study & Biochemical test & Number of patients & Time of assessment & $\begin{array}{l}\text { Prevalence of } \\
\text { hypopituita- } \\
\text { rism }\end{array}$ & Prevalence of GHD \\
\hline $\begin{array}{l}\text { Kreitschmann-Andermahr } \\
\text { et al. [2] }\end{array}$ & $\begin{array}{l}\text { Basal hormone values, ITT, } \\
\text { TRH-LHRH-arginine test }\end{array}$ & 40 & 27.3 months (mean) & $55 \%$ & $20 \%$ \\
\hline Aimaretti et al. [16] & $\begin{array}{l}\text { Basal hormone values, } \\
\text { GHRH-arginine test, } \\
\text { morning serum cortisol, } 24 \\
\text { urinary cortisol }\end{array}$ & 40 & 3 months & $37.5 \%$ & $25 \%$ \\
\hline Aimaretti et al. [39] & $\begin{array}{l}\text { Basal hormone values, } \\
\text { GHRH-arginine test, } \\
\text { morning serum cortisol, } 24 \\
\text { urinary cortisol }\end{array}$ & 32 & 12 months & $37.5 \%$ & $21.8 \%$ \\
\hline Dimopoulou et al. [15] & $\begin{array}{l}\text { Basal hormone values, IGF-1 } \\
\text { level, low dose ACTH test }\end{array}$ & 30 & $12-24$ months & $47 \%$ & $37 \%$ \\
\hline Tanriverdi et al. [14] & $\begin{array}{l}\text { Basal Hormone values (within } \\
24 \text { h) } \\
\text { GST, GHRH-arginine (12 } \\
\text { months) }\end{array}$ & 22 & $\begin{array}{l}\text { Within } 24 \mathrm{~h} \\
12 \text { months }\end{array}$ & $\begin{array}{l}63.6 \% \\
45 \%\end{array}$ & $\begin{array}{l}22.7 \% \\
36.4 \%\end{array}$ \\
\hline Jovanovic et al. [13] & Basal hormone values, IGF-1 & 93 & 1.8 years (mean) & $49.5 \%$ & $29 \%$ \\
\hline Klose et al. [21] & $\begin{array}{l}\text { ITT, SST, GHRH-arginine } \\
\text { test, clomiphene test }\end{array}$ & 62 & 14 months & $0 \%$ & $0 \%$ \\
\hline Parenti et al. [33] & $\begin{array}{l}\text { Basal hormone values, IGF-1 } \\
\text { levels }\end{array}$ & 60 & Within $72 \mathrm{~h}$ & $56.9 \%$ & $22 \%$ \\
\hline Lammert et al. [17] & $\begin{array}{l}\text { Basal hormone values, SST, } \\
\text { ITT* }\end{array}$ & 20 & 12 months & $15 \%$ & $15 \%$ \\
\hline Dutta et al. $[34]^{\mathrm{T}}$ & $\begin{array}{l}\text { Basal hormone values, IGF-1 } \\
\text { level }\end{array}$ & 60 & At or after 6 months & $31.6 \%$ & $15 \%$ \\
\hline Karaca et al. [29] & Basal hormone values, GST & 20 & 3 years & $20 \%$ & $20 \% *$ \\
\hline Gardner et al. [19] & GST, SST, GHRH-arginine & $\begin{array}{l}64 \\
50\end{array}$ & $\begin{array}{l}3 \text { months } \\
12 \text { months }\end{array}$ & $\begin{array}{l}45 \% \\
12 \%\end{array}$ & $\begin{array}{l}20 \% \\
10 \%\end{array}$ \\
\hline Hannon et al. [20] & ITT, GST, SST & 41 & 15 months & $14.6 \%$ & $13.3 \%(4 / 30)$ \\
\hline Khajeh et al. [22] (HIPS) & $\begin{array}{l}\text { Basal Hormone Values, } \\
\text { Ghrelin test (Baseline) +/- } \\
\text { metyrapone stimulation test } \\
\text { Baseline hormone values and } \\
\text { GHRH-arginine (6 months) } \\
\text { Basal hormone values and } \\
\text { GHRH-arginine test (14 } \\
\text { months) }\end{array}$ & $\begin{array}{l}84 \text { (baseline) } \\
72 \\
68\end{array}$ & $\begin{array}{l}32 \text { days (mean) } \\
6 \text { months } \\
14 \text { months }\end{array}$ & $\begin{array}{l}44 \% \\
31 \% \\
9 \%\end{array}$ & $\begin{array}{l}31 \% \\
11 \% \\
7 \%\end{array}$ \\
\hline Kronvall et al. [18] & $\begin{array}{l}\text { Basal hormone values, } \\
\text { GHRH-arginine test } \\
\text { Basal hormone values, } \\
\text { GHRH-arginine test, ITT, } \\
\text { SST }\end{array}$ & $\begin{array}{l}45 \\
44\end{array}$ & $\begin{array}{l}3-6 \text { months } \\
12-24 \text { months }\end{array}$ & $\begin{array}{l}27 \% \\
43 \%\end{array}$ & $\begin{array}{l}7 \% \\
25 \%\end{array}$ \\
\hline
\end{tabular}

To calculate the frequency of pituitary dysfunction at each time point, the actual number of patients at each follow-up time point is used as the denominator, rather than the number of patients at baseline. Studies providing pooled traumatic brain injury (TBI) and SAH data are not included

*ITT only performed in patients with suspected GHD and ACTH deficiency. 3 and 6 months data from this cohort not presented

${ }^{\mathrm{T}}$ Retrospective and prospective cohort

for GH Replacement [28]), were allowed to decline confirmatory testing of GH axis. Protocol details of the dynamic tests used is provided in the Appendix section.

\section{Assay and diagnostic criteria}

Prior to the 26th January 2015, plasma cortisol, fT4, TSH, prolactin, LH, FSH, testosterone and estradiol were analysed using Electrochemical Luminescent Immunoassay (Roche 
Cobas 8000). After this time, these measurements were analysed using competitive Chemiluminescent Immunoassay (Siemens Advia Centaur). ACTH and GH were analysed using Siemens Immulite 2000 Two Site Enzymatic Chemiluminescent Immunoassay. IGF-1 levels were analysed using Siemens Immulite 2000 Enzymatic Chemiluminescent Immunoassay.

ACTH deficiency was diagnosed as a failure to reach a peak cortisol value of $450 \mathrm{nmol} / \mathrm{L}$ on both the GST and SST. Severe GHD was diagnosed as a failure to reach a peak $\mathrm{GH}$ value of $3 \mu \mathrm{g} / \mathrm{L}$ on dynamic testing. Hypogonadotrophic hypogonadism in men was diagnosed if a low serum testosterone (morning sample) was associated with low or inappropriately normal gonadotrophin level. In premenopausal women, hypogonadotrophic hypogonadism was defined as low serum estradiol and inappropriately low gonadotrophins associated with amenorrhoea or oligomenorrhoea. In postmenopausal women, this was defined as inappropriately low gonadotrophins for age. Secondary hypothyroidism was defined as a low serum free $\mathrm{T} 4$ associated with low or inappropriately normal serum TSH.

\section{Statistical analyses}

Data analysis was carried out using IBM SPSS Statistics 22 (IBM SPSS Statistics for Windows, Version 22.0 Armonk, NY, USA: 2013). The prevalence of GHD was reported with descriptive statistics. Categorical data was analysed with either the Chi-squared test or the Fisher exact test where appropriate. Non-categorical data was analysed using the t-test or the Mann-Whitney $U$ test where appropriate. A two tailed $p$-value $<0.05$ was considered statistically significant.

\section{Results}

\section{Patient demographics and clinical features of subarachnoid haemorrhage}

One hundred patients (32 males and 68 females) were screened, with a mean age at screening of $57 \pm 10$ years (range 32-83 years). The mean age at time of SAH was $53 \pm 10$ years (range $24-78$ years) and the median interval from ictus to pituitary hormone testing was 35 months (range 14-117 months). The mean body weight was $74.6 \pm 15.1 \mathrm{~kg}$, with a BMI of $27.3 \pm 4.6$ and mean WHR of $0.89 \pm 0.08$. Majority of patients presented with WFNS grades 1 or 2 $(n=82)$ and the commonest Fisher grade was $4(n=39$; Table 2).

On angiographic studies, anterior circulation aneurysms $(\mathrm{n}=72)$ and notably anterior communicating artery aneurysms, $(n=27)$ were the commonest (Table 2). Presence of other incidental aneurysms (not source of acute bleeding) was noted in 21 (21\%) patients. Insertion of EVD was required in $16(16 \%)$ patients due to the development of hydrocephalus. Twenty-three patients had radiological evidence of vasospasm during the acute admission. In one patient, details regarding the acute in patient admission were not available as she was managed at different centre.

Interventional procedures were carried out in $86(86 \%)$ patients and this was either endovascular coiling or surgical clipping. Perimesencephalic type SAH was diagnosed in 14 (14\%) patients as no aneurysms were detected on neuroimaging and therefore these patients did not require endovascular or neurosurgical treatment. In four patients, multiple aneurysms were coiled during the acute episode (Table 2).

\section{Baseline pituitary profile and glucagon stimulation tests}

After screening GST, 37 (37\%) patients were diagnosed with some degree of hypopituitarism (Fig. 1). The most common deficiency was severe GHD which was diagnosed in twentyseven of patients, followed by ACTH deficiency in eighteen patients and lastly gonadotrophin deficiency in four patients. No cases of female hypogonadism were detected. No cases of TSH deficiency or hyperprolactinaemia were detected. In patients with GHD, sixteen patients had isolated GHD, ten patients had GHD in association with ACTH deficiency and one patient had GHD in association with hypogonadism.

\section{Short synacthen test}

Results of all patients with peak cortisol values less than $450 \mathrm{nmol} / \mathrm{L}$ on GST were reviewed. One patient had baseline cortisol of $328 \mathrm{nmol} / \mathrm{L}$ with a peak cortisol was $425 \mathrm{nmol} / \mathrm{L}$ on GST and this patient did not report any symptoms of cortisol deficiency. Another four patients had baseline cortisol results above $400 \mathrm{nmol} / \mathrm{L}$ and none of these patients had any symptoms of glucocorticoid insufficiency. As such these patients were thought overall to be ACTH sufficient. 11 patients completed the confirmatory SST, and all achieved a peak cortisol response of greater than $450 \mathrm{nmol} / \mathrm{L}$. Two patients did not attend their follow up SST (Fig. 1).

\section{Arginine stimulation test}

Following the initial GST and confirmatory testing of the ACTH axis, 26 patients were diagnosed with isolated GHD and therefore were required to undergo confirmatory testing of the somatotrophic axis. Six of these patients had QoLAGHDA score of less than 11 and thus did not meet NICE guidelines for GH replacement [28]. Five of these patients declined the confirmatory AST. Therefore, 21 patients underwent the AST and this confirmed isolated GHD in 13 patients (Fig. 1). 
Table 2 Clinical characteristics of SAH survivors included in our cohort

\begin{tabular}{|c|c|}
\hline & Number $(n=100)$ \\
\hline Male/female & $32 / 68$ \\
\hline Mean age at screening (months) & $57 \pm 10$ \\
\hline Mean age at time of SAH (months) & $53 \pm 10$ \\
\hline Median time from SAH to pituitary hormone testing (months) & 35 (IQR 22-73) \\
\hline Mean weight (kg) & $74.6 \pm 15.1$ \\
\hline Mean BMI & $27.3 \pm 4.6$ \\
\hline Mean WHR & $0.89 \pm 0.08$ \\
\hline \multicolumn{2}{|l|}{ Procedure } \\
\hline Endovascular coiling & 67 \\
\hline Neurosurgical clipping & 15 \\
\hline Multiple coiling procedures during acute admission & 4 \\
\hline None & 14 \\
\hline \multicolumn{2}{|l|}{ Location of aneurysm } \\
\hline \multicolumn{2}{|l|}{ Anterior circulation } \\
\hline Anterior communicating artery & 27 \\
\hline Middle cerebral artery & 19 \\
\hline Posterior communicating artery & 18 \\
\hline Internal carotid artery & 7 \\
\hline Pericallosal artery & 1 \\
\hline \multicolumn{2}{|l|}{ Posterior circulation } \\
\hline Basilar artery & 6 \\
\hline Posterior inferior cerebellar artery & 3 \\
\hline Vertebral artery & 1 \\
\hline Perimesencephalic & 14 \\
\hline Multiple aneurysms (unable to determine site of bleeding) & 4 \\
\hline \multicolumn{2}{|l|}{ WFNS } \\
\hline 1 & 69 \\
\hline 2 & 13 \\
\hline 3 & 4 \\
\hline 4 & 3 \\
\hline 5 & 6 \\
\hline Unavailable & 4 \\
\hline \multicolumn{2}{|l|}{ Fisher grade* } \\
\hline 1 & 13 \\
\hline 2 & 15 \\
\hline 3 & 11 \\
\hline 4 & 39 \\
\hline Too late & 2 \\
\hline Not available** & 6 \\
\hline \multicolumn{2}{|l|}{ GOS } \\
\hline 4 & 15 \\
\hline 5 & 85 \\
\hline QoL-AGHDA $\geq 11$ & 69 \\
\hline
\end{tabular}

*Patients presenting with perimesencephalic pattern SAH were not given Fisher score

**In these patients copies of admission imaging were not available electronically
After confirmatory testing, the total number of patients with GHD in our cohort was 14 (thirteen patients with isolated GHD and one patient with GHD combined with hypogonadism). Isolated gonadotrophin deficiency was noted in three further patients. Assuming that the two patients who did not attend follow up SST were ACTH deficient (given that we were not able to confirm this), the prevalence of hypopituitarism in our cohort is $19 \%$. 


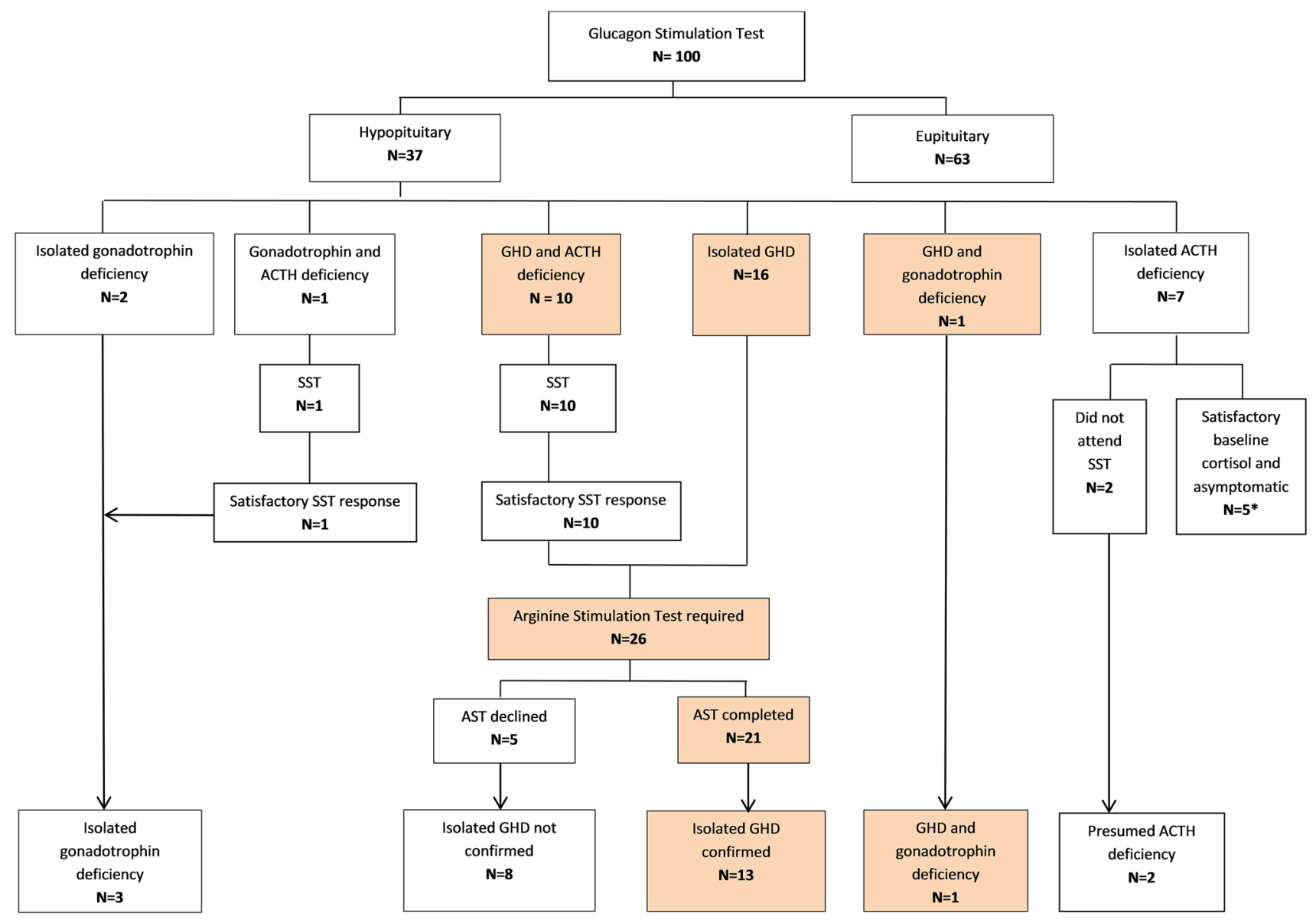

Fig. 1 Flowchart demonstrating progression of patients through the study protocol. Only male hypogonadism was detected in this cohort. *Five patients diagnosed with ACTH deficiency on GST, were deemed to be sufficient after results were re-reviewed (see results section)

\section{Factors related to GHD}

On univariate analysis, the differences in body weight, BMI and WHR between patients with GHD compared to patients without GHD were significant (Table 3). There was a negative correlation between peak GH level on GST and the patient's BMI $(\mathrm{R}=-0.52 ; \mathrm{p}<0.0001)$ and the WHR in our cohort $(\mathrm{R}=-0.43$; $\mathrm{p}<0.0001$; Fig. 2$)$.

On univariate analysis there was no significant difference between the patients with GHD and those without GHD, with respect to the mean age of onset of SAH ( $p=0.73)$, the age $(\mathrm{p}=0.66)$ and time to screening post SAH $(\mathrm{p}=0.25)$, the GCS at presentation $(p=0.52)$, WFNS grade $(p=0.58)$, site of aneurysm $(p=0.61)$, Fisher grade of SAH $(p=0.57)$, EVD insertion $(p=0.26)$, occurrence of vasospasm $(p=0.33)$ and treatment modality $(p=0.11$; Table 3$)$. Patients with GHD had worse GOS scores at screening than those without GHD $(\mathrm{p}=0.03$; Table 3$)$.

Logistic regression was carried out to assess how the covariates of BMI, WHR, ADGHA score, gender, age at screening and hydrocephalus were associated with GHD.
After running our models, all of which included BMI, gender, WHR, age, QoL-AGHDA score and GOS as covariates, we found the following to be positively associated with GHD: BMI (OR 1.527, 95\% CI 1.17-1.994), AGHDA score (OR 1.38, 95\% CI 1.102-1.737) and hydrocephalus (OR 7.671, 95\% CI 1.139-51.68). In spite of the small number of patients with GHD this model remained resilient. However the interpretation of these results should be done cautiously. For example the unfeasibly high upper confidence interval of hydrocephalus suggests an odds ratio of 51.68, and is unlikely to reflect the truth.

\section{Discussion}

This is a large study assessing endocrine function in SAH patients with dynamic testing of pituitary function. After the initial GST, GHD was detected in $27 \%$ of patients which is consistent with other studies employing this test $[19,29]$. Additional testing with the arginine stimulation test, reduced prevalence of GHD detected in our cohort to 
Table 3 Comparison between patients with confirmed GHD and those without GHD

\begin{tabular}{|c|c|c|c|}
\hline & GHD $(n=14)$ & Not GHD $(n=86)$ & p-value \\
\hline $\mathrm{M} / \mathrm{F}$ & $7 / 7$ & $24 / 61$ & $0.13^{\mathrm{a}}$ \\
\hline Mean weight (kg) & $88.3 \pm 13.3$ & $72.4 \pm 14.2$ & $<0.0001^{\mathrm{b}}$ \\
\hline Mean BMI (kg/m2) & $31.9 \pm 3.9$ & $26.6 \pm 4.5$ & $<0.0001^{\mathrm{b}}$ \\
\hline Mean WHR & $0.94 \pm 0.07$ & $0.88 \pm 0.08$ & $0.008^{\mathrm{b}}$ \\
\hline Mean age at presentation (years) & $52 \pm 10$ & $53 \pm 10$ & $0.73^{\mathrm{b}}$ \\
\hline Mean time to screening (months) & $34 \pm 18$ & $48 \pm 32$ & $0.25^{\mathrm{c}}$ \\
\hline Mean age at screening (years) & $55 \pm 10$ & $57 \pm 10$ & $0.66^{\mathrm{b}}$ \\
\hline Procedure & & & $0.11^{\mathrm{d}}$ \\
\hline None & 3 & 11 & \\
\hline Endovascular coiling & 7 & 60 & \\
\hline Clipping & 2 & 13 & \\
\hline Multiple endovascular coiling & 2 & 2 & \\
\hline Site of aneurysm & & & $0.61^{\mathrm{d}}$ \\
\hline \multicolumn{4}{|l|}{ Anterior circulation } \\
\hline Anterior communicating artery & 3 & 24 & \\
\hline Middle cerebral artery & 2 & 17 & \\
\hline Posterior communicating artery & 3 & 15 & \\
\hline Internal carotid artery & 0 & 7 & \\
\hline Pericallosal artery & 0 & 1 & \\
\hline \multicolumn{4}{|l|}{ Posterior circulation } \\
\hline Basilar artery & 1 & 5 & \\
\hline Posterior inferior cerebellar artery & 0 & 3 & \\
\hline Vertebral artery & 0 & 1 & \\
\hline Perimesencephalic & 3 & 11 & \\
\hline Multiple aneurysms & 2 & 2 & \\
\hline WFNS & & & $0.58^{\mathrm{d}}$ \\
\hline 1 & 10 & 59 & \\
\hline 2 & 3 & 10 & \\
\hline 3 & 0 & 4 & \\
\hline 4 & 1 & 2 & \\
\hline 5 & 0 & 6 & \\
\hline Fisher & & & $0.57^{\mathrm{d}}$ \\
\hline 1 & 3 & 10 & \\
\hline 2 & 2 & 13 & \\
\hline 3 & 1 & 10 & \\
\hline 4 & 4 & 35 & \\
\hline GOS & & & $0.03^{\mathrm{a}}$ \\
\hline 4 & 5 & 10 & \\
\hline 5 & 9 & 76 & \\
\hline
\end{tabular}

Fisher grading on admission was not available for eight patients. WFNS grading on admission was not available for four patients

${ }^{\mathrm{a}} \mathrm{Chi}$-square test

${ }^{\mathrm{b}} t$ test

${ }^{\mathrm{c}}$ Mann-Whitney $U$ test

${ }^{\mathrm{d}}$ Fisher exact test
$14 \%$ and the prevalence of hypopituitarism to $19 \%$. This is consistent with more recent studies that incorporated confirmatory testing [18-20]. This study also confirms that isolated GHD is the most common pituitary hormone deficiency post subarachnoid haemorrhage.

The retrospective method of recruitment in this study is likely to favour patients with better clinical outcomes and 

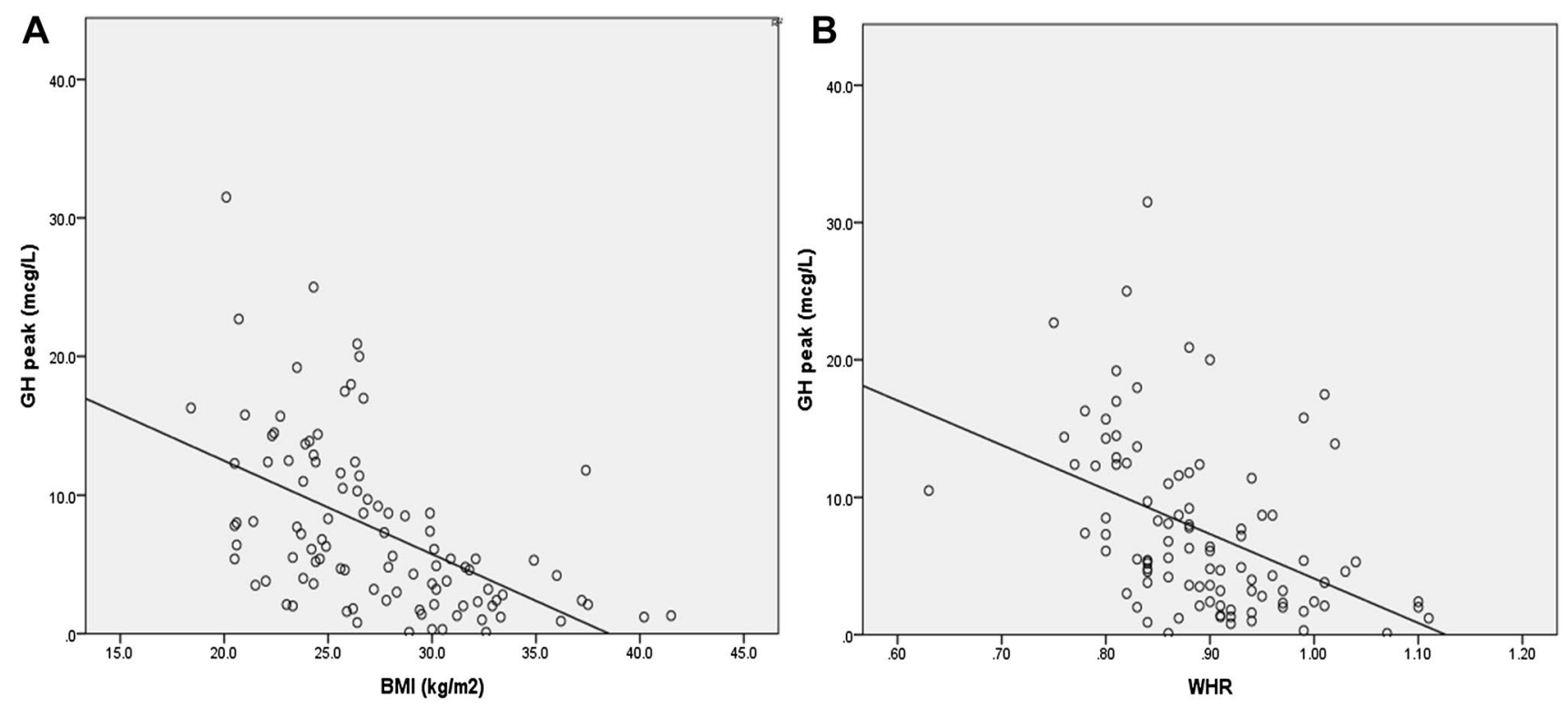

Fig. 2 Correlation between peak GH on GST with BMI and WHR. a Peak GH response on GST versus BMI in all patients in our cohort, $\mathrm{R}=-0.519(\mathrm{p}<0.001)$, b Peak GH response on GST versus waist to hip ratio (WHR), $\mathrm{R}=-0.434(\mathrm{p}<0.001)$

less severe SAH. This is reflected by the high proportion of survivors with good WFNS grade and GOS score at screening in our cohort and may not truly reflect the risk of hypopituitarism after severe SAH. However, this preponderance of patients with mild-moderate clinical severity and high proportion of treatment via the endovascular route is similar to other modern cohorts [19-21]. It is noted however, that the radiological severity as measured by the Fisher grade in our cohort is less severe than other studies and this might confound our results. Perimesencephalic-type SAH is associated with good clinical outcome [30] and the inclusion of these patients (14\%) in our analysis may additionally contribute to the low prevalence of GHD in our cohort.

As it was not compulsory for participants to undergo confirmatory testing of the somatotrophic axis if the QoLAGHDA score was $<11$, it is possible that the prevalence of isolated GHD is slightly underestimated in our cohort. It is understandable that some participants who did not meet NICE criteria for GHR were reluctant to re-attend our centre for a second dynamic test, as they were not eligible for GHR. Additional factors such as poor mental and physical health were contributory factors for the poor compliance in this regard. However this does highlight one of the difficulties in conducting a 'real life' clinical study in this patient population and should be considered when planning further studies involving this patient group.

The variation in reported prevalence of hypopituitarism and GHD in the literature is most likely reflective of the heterogeneous endocrine tests used to diagnose hormonal deficiency, different time points of endocrine assessment and varying thresholds for defining GHD [23, 31, 32]. Indeed, several of previous studies relied solely on low serum IGF-1 concentrations to diagnose GHD $[13,15,33$, 34], in spite of its limited diagnostic accuracy [35-37]. Additionally, even though isolated GHD is consistently reported as the most common deficiency post $\mathrm{SAH}$, few studies confirm this with a second dynamic test [19-21]. The potential to misdiagnose isolated GHD on a single dynamic test is well established [38] and as such it is likely that studies that have only relied on a single test may over-estimate the prevalence of GHD [14, 39]. Studies that have employed dynamic pituitary tests and subsequent confirmatory testing report a lower prevalence of GHD of between 0 and $13.3 \%$ [19-21]. Therefore the size of our study and the use of two different dynamic tests to confirm GHD strengthens the validity of our results.

The difference in terms of weight, BMI and WHR between patients with confirmed GHD and those with adequate GH response in our cohort, was statistically significant. Although it has been demonstrated that GHD in adults is associated with increased weight, body fat and central adiposity [40, 41], it is unclear if our findings are truly reflective of this and therefore causality cannot be assumed. The GST has been shown to overestimate GHD in overweight adults with no known pituitary disease [42]. We have demonstrated an inverse correlation between the peak GH on GST and both BMI and WHR. Obesity is recognised as a confounder of GH response [42-44]. The mechanism by which glucagon stimulates GH release is unclear, however it is not unreasonable to postulate that it may be affected by 
the metabolic consequences associated with weight gain and central adiposity.

Even other stimulatory tests, such as the insulin tolerance test (ITT) and growth hormone releasing hormone (GHRH)-arginine stimulation test, show that GH response is BMI dependent $[44,45]$. It has even been suggested that waist circumference corrected cut-offs for GH peaks should be established [37] given that serum GH levels correlate inversely with WHR and abdominal fat in adults with no pituitary disease [46]. Diagnosing GHD in the presence of obesity can therefore be very challenging, and an appreciation of this is vital to ensure that results are interpreted with caution.

Interestingly, no difference in BMI between patients who were hypopituitary and those with normal pituitary function was demonstrated by Gardner et al., who employed GHRHarginine stimulation test with BMI-specific cut-offs in their cohort [19]. It is noteworthy that studies that incorporate the GHRH-arginine stimulation test with its validated BMIspecific cut-offs report the prevalence of GHD to be only be as high as $10 \%$ [18, 19, 21]. Kronvall et al. 2014, using the GHRH-arginine test reported a 7\% prevalence of GHD at 3-6 months and 25\% at 12-24 months testing [47]. However it is noted that at 12-24 months, patients were tested with either the ITT or GHRH-arginine and this may account for the higher prevalence of GHD detected at that time point. There are studies that have reported higher frequency of GHD even when GHRH-arginine stimulation test was used, however these studies did not incorporate current validated BMI specific cut-offs when diagnosing GHD [16, 39]. Therefore it is possible that GHD is also overestimated in our cohort, due to the limitations mentioned above. Further assessment of this cohort with a GHRH-arginine stimulation tests is recommended.

Like other studies, there was no association between development of GHD and clinical or radiological severity of SAH, GCS at presentation, age at presentation, treatment modality or the presence of vasospasm $[2,15,16,33]$ in this cohort.

Given the lack of clinical predictors of GHD in this patient population consensus guidelines recommend endocrine screening in all SAH survivors in whom there is an intention to treat $[48,49]$. However such a recommendation may have a significant impact on clinical practice. Routine screening for endocrine dysfunction in all SAH survivors with dynamic pituitary testing incurs a significant financial, logistic and work force requirement. Furthermore, such a screening process will subject a large number of patients to the unpleasant and on occasion detrimental side-effects associated with dynamic pituitary testing. Importantly, the value of detecting GHD in this patient population remains unclear, given that data regarding the impact or benefit of Growth Hormone Replacement in SAH survivors is scant.
Lastly, uncertainty exists as to whether development of pituitary dysfunction after SAH is permanent. Several authors including a recent meta-analysis, have demonstrated that the prevalence of pituitary dysfunction including that of the somatotrophic axis, can change with time $[14,19,22,23$, $29,39,47,50]$. As such it remains unclear whether pituitary function should be continually re-assessed in SAH patients, and if so, at what time points.

\section{Conclusion}

The prevalence of GHD in our cohort was $14 \%$, when dynamic pituitary testing and confirmatory testing was employed. The varied prevalence reported in the literature is likely due to heterogeneous testing methods. Even though there was a significant difference in terms of BMI and WHR in patients with and without GHD, this may be due to the testing methodology employed. Further testing with protocols that incorporate BMI-specific cut-offs are planned. Even though GHD is associated with worse quality of life as measured by the QoL-AGHDA score, there are no good clinical predictors of GHD. Although it is recommended that all SAH survivors be screened for endocrine dysfunction, this may not be always be feasible and has a substantial impact on resources. Further guidance is required as to which patients to assess, type of endocrine tests to use, timing of patient assessment and importantly which patients would derive clinical benefit from growth hormone testing and subsequently hormonal replacement.

Acknowledgements The authors would like to thank Ms Laura Johnstone for her clinical support, Dr Mark Guy for laboratory assistance. We would also like the Brain and Spinal Injury Centre (BASIC), Salford, for allowing us to place study posters in the centre.

Funding This study was partly funded by an Investigator-Initiated Research (IIR) award from Pfizer Ltd.

Author Contributions SG, JC, KG and TK conceived and designed the study. SG and JC carried out study procedures. DH reviewed and interpreted radiology images. SG and TK reviewed and analysed the data. $\mathrm{CH}$ provided statistical advice. SG drafted the manuscript. $\mathrm{KG}$ and TK reviewed and revised the manuscript for intellectual content. All authors approved the final manuscript.

\section{Compliance with ethical standards}

Conflict of interest All authors declare no conflict of interest that could prejudice the study reported.

Open Access This article is distributed under the terms of the Creative Commons Attribution 4.0 International License (http://creativecommons.org/licenses/by/4.0/), which permits unrestricted use, distribution, and reproduction in any medium, provided you give appropriate credit to the original author(s) and the source, provide a link to the Creative Commons license, and indicate if changes were made. 


\section{Appendix Clinical protocols for dynamic tests used}

\section{Glucagon stimulation test}

- After an overnight fast(from midnight onwards-water allowed) an intravenous cannula is inserted and allowed to rest for $30 \mathrm{~min}$

- Baseline sample for of GH, IGF-1, testosterone/estradiol, LH, FSH, cortisol, ACTH, fT4, TSH and prolactin is drawn.

- Glucagon (GlucaGen, Novonordisk Ltd) is administered subcutaneously at a dose of $1 \mathrm{mg}(1.5 \mathrm{mg}$ for patients $>100 \mathrm{kgs}$ ).

- Blood samples for GH and cortisol are taken at 90, 120, 150, 180, 210 and $240 \mathrm{~min}$.

\section{Arginine stimulation test}

- After an overnight fast as above, intravenous cannulae are inserted into both forearms and are allowed to rest for $30 \mathrm{~min}$

- A baseline blood sample is taken at $0 \mathrm{~min}$ for $\mathrm{GH}$

- $30 \mathrm{~g}$ arginine is infused over $30 \mathrm{~min}$ (150 mls of $20 \%$ L-arginine hydrochloride (Stockport Pharmaceuticals, $\mathrm{UK})$ )

- Blood samples for GH are taken at 30, 60, 90 and $120 \mathrm{~min}$.

\section{Short synacthen test}

- Following an overnight fast as above, an indwelling peripheral venous cannula is inserted and allowed to rest for $30 \mathrm{~min}$

- Baseline blood sample for cortisol measurement is drawn

- Intramuscular injection of $250 \mu \mathrm{g}$ of synacthen (Tetracosactide, Questcor Operations, UK) is administered

- Blood samples for cortisol are drawn at 30 and $60 \mathrm{~min}$.

\section{References}

1. Quinn AC, Bhargava D, Al-Tamimi YZ, Clark MJ, Ross SA, Tennant A (2014) Self-perceived health status following aneurysmal subarachnoid haemorrhage: a cohort study. BMJ Open 4(4):e003932

2. Kreitschmann-Andermahr I, Hoff C, Saller B, Niggemeier S, Pruemper S, Hutter BO et al (2004) Prevalence of pituitary deficiency in patients after aneurysmal subarachnoid hemorrhage. J Clin Endocrinol Metab 89(10):4986-4992

3. Rinkel GJE, Algra A (2011) Long-term outcomes of patients with aneurysmal subarachnoid haemorrhage. Lancet Neurol 10(4):349-356

4. Visser-Meily JMA, Rhebergen ML, Rinkel GJE, van Zandvoort MJ, Post MWM (2009) Long-term health-related quality of life after aneurysmal subarachnoid hemorrhage relationship with psychological symptoms and personality characteristics. Stroke 40(4):1526-1529

5. Wong GKC, Poon WS, Boet R, Chan MTV, Gin T, Ng SCP et al (2011) Health-related quality of life after aneurysmal subarachnoid hemorrhage: profile and clinical factors. Neurosurgery 68(6):1556-1561

6. Ronne-Engstrom E, Enblad P, Lundstrom E (2013) Health-related quality of life at median 12 months after aneurysmal subarachnoid hemorrhage, measured with EuroQoL-5D. Acta Neurochir 155(4):587-593

7. Tjahjadi M, Heinen C, Koenig R, Rickels E, Wirtz CR, Woischneck D et al (2013) Health-related quality of life after spontaneous subarachnoid hemorrhage measured in a recent patient population. World Neurosurg 79(2):296-307

8. Noble AJ, Baisch S, Mendelow AD, Allen L, Kane P, Schenk T (2008) Posttraumatic stress disorder explains reduced quality of life in subarachnoid hemorrhage patients in both the short and long term. Neurosurgery 63(6):1095-1104

9. Scott RB, Eccles F, Molyneux AJ, Kerr RSC, Rothwell PM, Carpenter K (2010) Improved cognitive outcomes with endovascular coiling of ruptured intracranial aneurysms neuropsychological outcomes from the international subarachnoid aneurysm trial (ISAT). Stroke 41(8): 1743-1747

10. Kronvall E, Sonesson B, Valdemarsson S, Siemund R, Säveland H, Nilsson OG (2016) Reduced quality of life in patients with pituitary dysfunction after aneurysmal subarachnoid hemorrhage: a prospective longitudinal study. World Neurosurg 88:83-91

11. Khajeh L, Ribbers GM, Heijenbrok-Kal MH, Blijdorp K, Dippel DWJ, Sneekes EM et al (2016) The effect of hypopituitarism on fatigue after subarachnoid hemorrhage. Eur J Neurol 23(8):1269-1274

12. Kelly DF, Gonzalo IT, Cohan P, Berman N, Swerdloff R, Wang C (2000) Hypopituitarism following traumatic brain injury and aneurysmal subarachnoid hemorrhage: a preliminary report. J Neurosurg 93(5):743-752

13. Jovanovic V, Pekic S, Stojanovic M, Tasic G, Djurovic B, Soldatovic I et al (2010) Neuroendocrine dysfunction in patients recovering from subarachnoid hemorrhage. Hormones 9(3):235-244

14. Tanriverdi F, Dagli AT, Karaca Z, Unluhizarci K, Selcuklu A, Casanueva FF et al (2007) High risk of pituitary dysfunction due to aneurysmal subarachnoid haemorrhage: a prospective investigation of anterior pituitary function in the acute phase and 12 months after the event. Clin Endocrinol 67(6):931-937

15. Dimopoulou I, Kouyialis AT, Tzanella M, Armaganidis A, Thalassinos N, Sakas DE et al (2004) High incidence of neuroendocrine dysfunction in long-term survivors of aneurysmal subarachnoid hemorrhage. Stroke 35(12):2884-2889

16. Aimaretti G, Ambrosio MR, Di Somma C, Fusco A, Cannavo $\mathrm{S}$, Gasperi $\mathrm{M}$ et al (2004) Traumatic brain injury and subarachnoid haemorrhage are conditions at high risk for hypopituitarism: screening study at 3 months after the brain injury. Clin Endocrinol 61(3):320-326

17. Lammert A, Bode H, Hammes HP, Birck R, Fatar M, Zohsel K et al (2012) Aneurysmal subarachnoid hemorrhage (aSAH) results in low prevalence of neuro-endocrine dysfunction and NOT deficiency. Pituitary 15(4):505-512

18. Kronvall E, Valdemarsson S, Saveland H, Nilsson OG (2014) Pituitary dysfunction after aneurysmal subarachnoid hemorrhage 
is associated with impaired early outcome. World Neurosurg 81(3-4):529-537

19. Gardner CJ, Javadpour M, Stoneley C, Purthuran M, Biswas S, Daousi C et al (2013) Low prevalence of hypopituitarism after subarachnoid haemorrhage using confirmatory testing and with BMI-specific GH cut-off levels. Eur J Endocrinol 168(4):473-481

20. Hannon MJ, Behan LA, O'Brien MM, Tormey W, Javadpour M, Sherlock M et al (2014) Chronic hypopituitarism is uncommon in survivors of aneurysmal subarachnoid haemorrhage. Clin Endocrinol 82:115-121

21. Klose M, Brennum J, Poulsgaard L, Kosteljanetz M, Wagner A, Feldt-Rasmussen U (2010) Hypopituitarism is uncommon after aneurysmal subarachnoid haemorrhage. Clin Endocrinol 73(1):95-101

22. Khajeh L, Blijdorp K, Heijenbrok-Kal MH, Sneekes EM, van den Berg-Emons HJG, van der Lely AJ et al (2014) Pituitary dysfunction after aneurysmal subarachnoid haemorrhage: course and clinical predictors the HIPS study. J Neurol Neurosurg Psychiatry 86(8):905-910

23. Can A, Gross BA, Smith TR, Dammers R, Dirven CMF, Woodmansee WW et al (2016) Pituitary dysfunction after aneurysmal subarachnoid hemorrhage: a systematic review and meta-analysis. Neurosurgery 79(2):253-263

24. Drake CG (1988) Report of World-Federation-of-NeurologicalSurgeons Committee on a Universal subarachnoid hemorrhage Grading Scale. J Neurosurg 68(6):985-986

25. Fisher CM, Kistler JP, Davis JM (1980) Relation of cerebral vasospasm to subarachnoid hemorrhage visualized by computerized tomographic scanning. Neurosurgery 6(1):1-9

26. Jennett B, Bond M (1975) Assessment of outcome after severe brain-damage - practical scale. The Lancet 1(7905):480-484

27. NICE. Quality of life. Assessment of GH deficiency in adults. https://www.nice.org.uk/guidance/ta64/documents/ questionnaire-quality-of-life-assessment-of-deficiency-in-adults2.

28. (NICE) NIoHaCE (2003) Human growth hormone (somatropin) in adults with growth hormone deficiency. https://www.nice.org. uk/guidance/ta64

29. Karaca Z, Tanriverdi F, Dagli AT, Selcuklu A, Casanueva FF, Unluhizarci $\mathrm{K}$ et al (2013). Three years prospective investigation of pituitary functions following subarachnoid haemorrhage. Pituitary. 16(1):76-82

30. Flaherty ML, Haverbusch M, Kissela B, Kleindorfer D, Schneider A, Sekar P et al (2005) Perimesencephalic subarachnoid hemorrhage: incidence, risk factors, and outcome. J Stroke Cerebrovasc Dis 14(6):267-271

31. Ioachimescu AG, Barrow DL (2015) Subarachnoid hemorrhage and the pituitary. World Neurosurg 83(6):1026-1028

32. Schneider HJ, Kreitschmann-Andermahr I, Ghigo E, Stalla GK, Agha A (2007) Hypothalamopituitary dysfunction following traumatic brain injury and aneurysmal subarachnoid hemorrhage: a systematic review. Jama 298(12):1429-1438

33. Parenti G, Cecchi PC, Ragghianti B, Schwarz A, Ammannati F, Mennonna $P$ et al (2011) Evaluation of the anterior pituitary function in the acute phase after spontaneous subarachnoid hemorrhage. J Endocrinol Invest 34(5):361-365

34. Dutta P, Mukherjee KK, Chaudhary PK, Masoodi SR, Anand S, Pathak A et al (2012) Pituitary dysfunction in survivors of spontaneous subarachnoid hemorrhage of anterior communicating artery and middle cerebral artery aneurysms: a comparative study. Neurology India 60(4):390-394

35. Svensson J, Johannsson G, Bengtsson BA (1997) Insulin-like growth factor-I in growth hormone-deficient adults: Relationship to population-based normal values, body composition and insulin tolerance test. Clin Endocrinol 46(5):579-586

36. Toogood AA, Jones J, O'Neill PA, Thorner MO, Shalet SM (1998) The diagnosis of severe growth hormone deficiency in elderly patients with hypothalamic-pituitary disease. Clin Endocrinol 48(5):569-576

37. Andersen M (2015) The robustness of diagnostic tests for GH deficiency in adults. Growth Horm IGF Res 25(3):108-114

38. Lissett CA, Thompson EGE, Rahlm A, Brennan BMD, Shalet SM (1999) How many tests are required to diagnose growth hormone (GH) deficiency in adults? Clin Endocrinol 51(5):551-557

39. Aimaretti G, Ambrosio MR, Di Somma C, Gasperi M, Cannavo S, Scaroni $C$ et al (2005) Residual pituitary function after brain injury-induced hypopituitarism: a prospective 12-month study. J Clin Endocrinol Metab 90(11):6085-6092

40. Bengtsson BA (1998) Untreated growth hormone deficiency explains premature mortality in patients with hypopituitarism. Growth Horm IGF Res 8:77-80

41. Hoffman AR, Kuntze JE, Baptista J, Baum HBA, Baumann GP, Biller BMK et al (2004) Growth hormone (GH) replacement therapy in adult-onset GH deficiency: effects on body composition in men and women in a double-blind, randomized, placebocontrolled trial. J Clin Endocrinol Metab 89(5):2048-2056

42. Dichtel LE, Yuen KCJ, Bredella MA, Gerweck AV, Russell BM, Riccio AD et al (2014) Overweight/obese adults with pituitary disorders require lower peak growth hormone cutoff values on glucagon stimulation testing to avoid overdiagnosis of growth hormone deficiency. J Clin Endocrinol Metab 99(12):4712-4719

43. Klose M, Feldt-Rasmussen U (2015) Hypopituitarism in traumatic brain injury-a critical note. J Clin Med 4(7):1480-1497

44. Corneli G, Di Somma C, Baldelli R, Rovere S, Gasco V, Croce CG et al (2005) The cut-off limits of the GH response to GHreleasing hormone-arginine test related to body mass index. Eur J Endocrinol 153(2):257-264

45. Biller BMK, Samuels MH, Zagar A, Cook DM, Arafah BM, Bonert V et al (2002) Sensitivity and specificity of six tests for the diagnosis of adult GH deficiency. J Clin Endocrinol Metab 87(5):2067-2079

46. Vahl N, Jorgensen JOL, Skjaerbaek C, Veldhuis JD, Orskov H, Christiansen JS (1997) Abdominal adiposity rather than age and sex predicts mass and regularity of GH secretion in healthy adults. Am J Physiol-Endocrinol Metab 272(6):E1108-E1116

47. Kronvall E, Sonesson B, Valdemarsson S, Siemund R, Saveland H, Nilsson OG (2016) Reduced quality of life in patients with pituitary dysfunction after aneurysmal subarachnoid hemorrhage: a prospective longitudinal study. World Neurosurg 88:83-91

48. Ho KKY, Works GHDC (2007) Consensus guidelines for the diagnosis and treatment of adults with GH deficiency II: a statement of the GH research society in association with the European Society for Pediatric Endocrinology, Lawson Wilkins Society, European Society of Endocrinology, Japan Endocrine Society, and Endocrine Society of Australia. Eur J Endocrinol 157(6):695-700

49. Gross BA, Laws ER (2015) Pituitary dysfunction after aneurysmal subarachnoid hemorrhage. World Neurosurg 83(6):1039-1040

50. Kopczak A, Krewer C, Schneider M, Kreitschmann-Andermahr I, Schneider HJ, Stalla GK (2015) The development of neuroendocrine disturbances over time: longitudinal findings in patients after traumatic brain injury and subarachnoid hemorrhage. Int $\mathbf{J}$ Mol Sci 17(1):2 